\title{
BMJ Open How GPs adapted their practices and organisations at the beginning of COVID-19 outbreak: a French national observational survey
}

Olivier Saint-Lary (D) , 1,2,3 Sylvain Gautier, ${ }^{1,4}$ Julien Le Breton, 5,6,7,8 Serge Gilberg, ${ }^{3,9}$ Paul Frappé, ${ }^{10}$ Matthieu Schuers, ${ }^{11}$ Yann Bourgueil, ${ }^{4}$ Vincent Renard ${ }^{3,5}$

To cite: Saint-Lary 0 , Gautier S, Le Breton J, et al. How GPs adapted their practices and organisations at the beginning of COVID-19 outbreak: a French national observational survey. BMJ Open 2020;10:e042119. doi:10.1136/ bmjopen-2020-042119

- Prepublication history and additional material for this paper is available online. To view these files, please visit the journal online (http://dx.doi.org/10. 1136/bmjopen-2020-042119).

Received 29 June 2020 Revised 09 November 2020 Accepted 10 November 2020

Check for updates

(C) Author(s) (or their employer(s)) 2020. Re-use permitted under CC BY-NC. No commercial re-use. See rights and permissions. Published by BMJ.

For numbered affiliations see end of article.

Correspondence to Professor Olivier Saint-Lary; oliviersaintlary@hotmail.com

\section{ABSTRACT}

Objectives To describe how general practitioners (GPS) adapted their practices to secure and maintain access to care in the epidemic phase. A secondary objective was to explore if GPs' individual characteristics and type of practice determined their adaptation.

Design Observational study using an online questionnaire. Organisational changes were measured by a main question and detailed in two specific outcomes. To identify which GPs' characteristics impacted organisational changes, successive multivariate logistic modelling was performed. First, we identified the GPs' characteristics related to organisational changes with a univariate analysis. Then, we tested the adjusted associations between this variable and the following GPs' characteristics: age, gender and type of practice.

Setting The questionnaire was administered online between 14 March and 21 March 2020. Practitioners were recruited by email using the contact lists of different French scientific GP societies.

Participants The target population was GPs currently practising in France $(n=46056)$. We obtained a total of 7481 responses.

Primary and secondary outcome measures Primary outcome: Proportion of GPs who adapted their practice. Secondary outcome: GPs' characteristics related to organisational changes.

Results Among the 7481 responses, 5425 were complete and were analysed. 3849 GPs (70.9\%) changed their activity, 3605 GPs (66.5\%) increased remote consultations and 2315 GPs (42.7\%) created a specific pathway for probable patients with COVID-19. Among the $3849 \mathrm{GPS}$ $(70.9 \%)$ who changed their practice, $3306(91.7 \%)$ gave more answers by phone, 996 (27.6\%) by email and 1105 $(30.7 \%)$ increased the use of video consultations. GPs working in multi-professional group practices were more likely to have changed their activity since the beginning of the epidemic wave than GPs working in mono-professional group or single medical practices (adjusted OR: 1.32, $95 \% \mathrm{Cl} 1.12$ to $1.56, \mathrm{p}=0.001$ ).

Conclusions French GPs adapted their practices regarding access to care for patients in the context of the COVID-19 epidemic. This adaptation was higher in multiprofessional group practices.
Strengths and limitations of this study

- This is the first French national study presenting adaptive strategies of general practitioners (GPs) at an early stage of the outbreak. Response rate to the survey was $11.8 \%$ of all active French GPs.

- In the context of the COVID-19 epidemic $70.9 \%$ of the responding French GPs adapted their practices regarding access to care for patients. This adaptation was organised in a context of a lack of PPE (protectivepersonal equipment) and was higher in multi-professional group practices.

- GPs who participated were younger than the average among French GPs (45.8 vs 50.7 ). The proportion of women was higher $(53.7 \%$ vs $44 \%)$ and they worked more frequently in multi-professional settings $31 \%$ vs $15 \%$. This selection bias could have resulted in an overestimation of the adaptation of practices in our sample.

\section{INTRODUCTION}

The spread of the COVID-19 outbreak among the general population has been a full-scale test for every health system around the world. Due to uncertainty regarding the COVID-19 epidemiology, action plans rely mostly on containment of the disease, a delay of dissemination by social distancing and a mitigation of impact by future vaccination and treatment issues based on research. The place of primary care in the management of the outbreak is crucial: ${ }^{1}$ only the most severe patients are hospitalised while the diagnosis is largely carried out by general practitioners (GPs). ${ }^{2}$ Simultaneously, maintaining the follow-up of patients with chronic and acute diseases, such as people who are disabled and frail at home and in institutions, is also a huge challenge for the first line of care in all of its components. The success of action plans relies on personal behaviour but also on the 
ability of primary care providers to adapt their practices and organisations to a new strategy.

France, where the first case was diagnosed on 24 January 2020 is one of the main countries in Europe that was faced with a rapid increase in cases. Due to the lack of protection devices and a poor diagnostic testing capacity, the French strategy was based on containment and social distancing in order to delay the increase in acute patients in hospitals. In the first national guidelines, published at the end of February, primary care providers were mentioned marginally. On 16 March 2020, the same day as the epidemic stage 3 was declared in France according to the WHO criteria, the first version of an extensive guideline towards primary care was elaborated. ${ }^{3}$ It emphasised mainly the use of telemedicine by physicians, and provided general recommendations about dedicated areas in waiting rooms, social distancing measures and hygiene rules. The establishment of dedicated territorial care pathways for probable patients with COVID-19 was not mentioned.

France has a primary care sector which can be qualified as a non-hierarchical professional model ${ }^{4}$ with a large number of providers, most of them working as private independent professionals paid by fees from public funding (National Health Insurance). Many changes have occurred gradually over the last 20 years, with an increase in academic positions for GPs and the definition of GP's role and primary care providers by law. GPs work mainly in groups ${ }^{5}$ and the number of multi-professional practices is expanding, with the support of national policies pushing for more coordination in primary care at the team-practice level but also at the local territorial level to better organise primary care towards the population's need. ${ }^{6}$ Despite public policy to change primary care, information system from the field is weak and little is known about organisation, practice and performance of this healthcare sector. In this context, we described how GPs in various settings all over the country adapted their practices to face the epidemic wave. We aimed to disseminate the results to professionals and decision-makers, to validate and eventually adapt the guidelines. This study was developed by a larger national consortium ACCORD, which was initiated to perform research through professional networks and to enhance the development of the primary care field by the production of scientific knowledge in primary care practices.

As we had no quantitative information about GPs' adaptations in the context of outbreak, the main objective was to describe to what extent GPs adapted their practices to secure and maintain access to care in the epidemic phase. Our secondary objective was to explore if GP's individual characteristics and type of practice determined their adaptation.

\section{METHODS}

Using an online questionnaire, we conducted a first national flash survey among French GPs currently practising in France.

\section{Survey instrument}

The instrument was designed by seven authors from different specialties (GPs, public health researchers and epidemiologists). The questions, written in French, focussed on protective personal equipment (PPE), hygiene measures, organisational changes, specific pathways for patients with COVID-19 and information sources about the outbreak.

\section{Screening and recruitment}

The questionnaire was administered through the free online software LimeSurvey. Twenty-four GPs pre-tested the online questionnaire in order to check its comprehensibility and acceptability.

The survey period occurred between 14 March and 21 March 2020. One reminder was sent before the end of the survey period.

The target population was GPs currently practising in France $(n=46056$ in statutory health insurance database 2019). ${ }^{7}$ Considering the surveyed population and an ideal random sampling strategy, the minimum sample size was 2283 GPs with a margin of error of $2 \%$ at a $95 \%$ confidence level. Practitioners were recruited by email using the contact lists of the different French scientific societies of GPs, which represent approximately 25000 GPs, that is, $54.3 \%$ of the study population. Moreover, in order to collect data rapidly, a snowball sampling strategy was finally applied. To discuss the external validity of the results, the selection bias was analysed by comparison of the sample characteristics with existing validated data about French GPs.

\section{Variables}

Organisational changes were measured through a main question 'did you change your activity?' $(\mathrm{n}=5425)$ and detailed in two specific outcomes: increase in remote consultations and the creation of a specific pathway.

The increase in remote consultations was measured through a binary variable describing whether the responding GP had increased the volume of their remote consultations (by email, phone or using teleconsultation tools). This variable was obtained from responses to three separate questions related to changes in the GP's activity since the start of the COVID-19 outbreak. The creation of a specific pathway was measured through a binary variable assessing the introduction of a specific pathway for probable patients with COVID-19 in the GP's practice. This variable was obtained from one separate question related to changes in the GP's activity since the start of the COVID-19 outbreak.

Predictors: factors potentially associated with organisational changes.

We assessed the potential impact on organisational changes of GPs' age, gender and type of practice. GPs' age was coded continuously. The type of practice was measured with a binary variable distinguishing GPs working in multiprofessional group practices from GPs working in monoprofessional groups or single medical practices. 


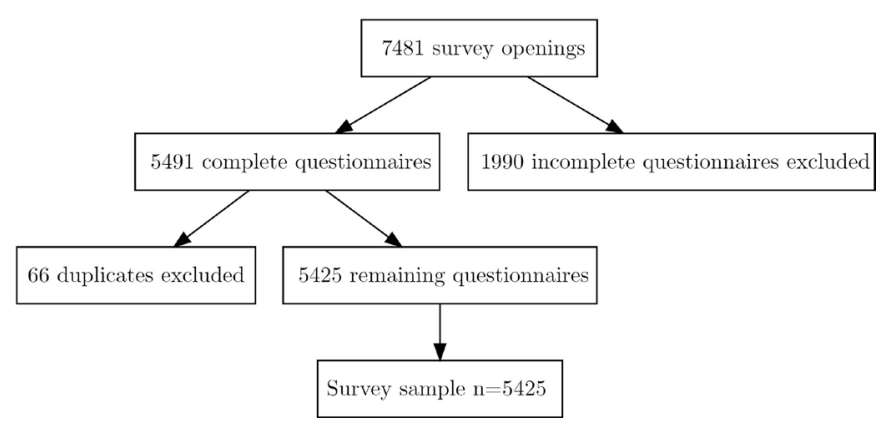

Figure 1 Flow chart.

\section{Analysis}

Modelling the probability of the organisational changes.

To identify which GPs' characteristics impacted the organisational changes, a successive multivariate logistic modelling was performed in two steps. In the first step, we identified which GPs' characteristics were related to organisational changes with a univariate analysis. The comparison of proportions was done with the Pearson's $\chi^{2}$ test. Then, we tested the adjusted associations between the organisational changes and the following GPs' characteristics: age, gender and type of practice. The comparisons and regressions presented in the rest of the article are, unless otherwise stated, significant at the 5\% threshold.

The study data were handled confidentially in accordance with the Commission Nationale de l'Informatique et Liberté (CNIL, approval no. 2217247). Data management, descriptive statistical analysis and modelling were carried out using software R V.4.0.

\section{Patient and public involvement}

No patients were involved.

\section{RESULTS}

We obtained a total of 7481 responses to the questionnaire. From these, 5491 survey forms, including 66 duplicates, were fully completed. A total of 5425 unique complete responses were thus analysed (figure 1). The obtained sample of respondents was higher than the expected sample size $(+138 \%)$. Considering the number of GPs currently practising in France in 2019, we estimated an average response rate of $11.8 \%$. The number of respondents varied by geographical area, (see online supplemental table 1) but the response rate was roughly the same from one county to another (figure 2). The mean age was 45.8 (SD: 12.2) and 2914 (53.7\%) respondents were women. One thousand and thirty-five GPs $(19.1 \%)$ worked in a single medical practice and 2226 $(41.0 \%)$ worked in a mono-professional group practice. Among the 2164 (39.9\%) GPs working in a multiprofessional group practice, $1411(65.2 \%)$ worked in a multidisciplinary health house and 269 (12.4\%) worked in an associative or municipal healthcare centre. Four thousand four hundred and fifty GPs $(82.0 \%)$ had a secretariat (reception staff or telephone secretary). One in four GPs offered unscheduled consultations. The characteristics of the respondents are summarised in table 1 .

Regarding PPE, 4699 GPs (86.6\%) had masks, 1402 (25.8\%) had protective glasses and 1148 (21.2\%) had aprons. Regarding hygiene and protective measures, 2874 GPs $(53.0 \%)$ provided their patients with hydroalcoholic solutions, $4603(84.8 \%)$ had communication supports detailing protective measures and $62.8 \%$ of GPs with masks were wearing one all day long $(n=2951)$. Detailed data are summarised in table 2 and online supplemental tables 2-4.

Regarding organisational changes, 3849 GPs (70.9\%) changed their activity, 3605 GPs $(66.5 \%)$ increased remote consultations and 2315 GPs $(42.7 \%)$ created a dedicated waiting area for COVID-19 suspected patients. More than one-third of the practitioners had a reception staff $(\mathrm{n}=1961,36.1 \%) ; 72.3 \%$ of those receptionists $(\mathrm{n}=1418)$ wore a mask and $84.8 \%(\mathrm{n}=1662)$ were trained to identify COVID-19 suspected patients. Among the 1383 GPs offering unscheduled consultations, one-third chose to cancel them and another one-third chose to adapt them to the epidemic wave. Among the 2798 GPs (51.6\%) with the possibility of creating a dedicated waiting area for COVID-19 suspected patients, 2315 (82.7\%) actually created one.

Among the 3849 GPs $(70.9 \%)$ who changed their way of practising, $3306(85.9 \%)$ gave more answers to their patients by phone, $996(25.9 \%)$ gave more answers by email and $1105(28.7 \%)$ increased their use of video consultations. One-third of the respondents $(n=1972)$ created a specific pathway for COVID-19 suspected patients, by introducing dedicated consultations ( $\mathrm{n}=1516,76.9 \%)$, visiting them at home $(\mathrm{n}=253,12.8 \%)$ or through a reorganisation of work duties among professionals $(n=769$, $39.0 \%$ ). The detailed data are summarised in tables 2 and $3 \mathrm{~A}$ and online supplemental table 5 . The table $3 \mathrm{~B}$ details

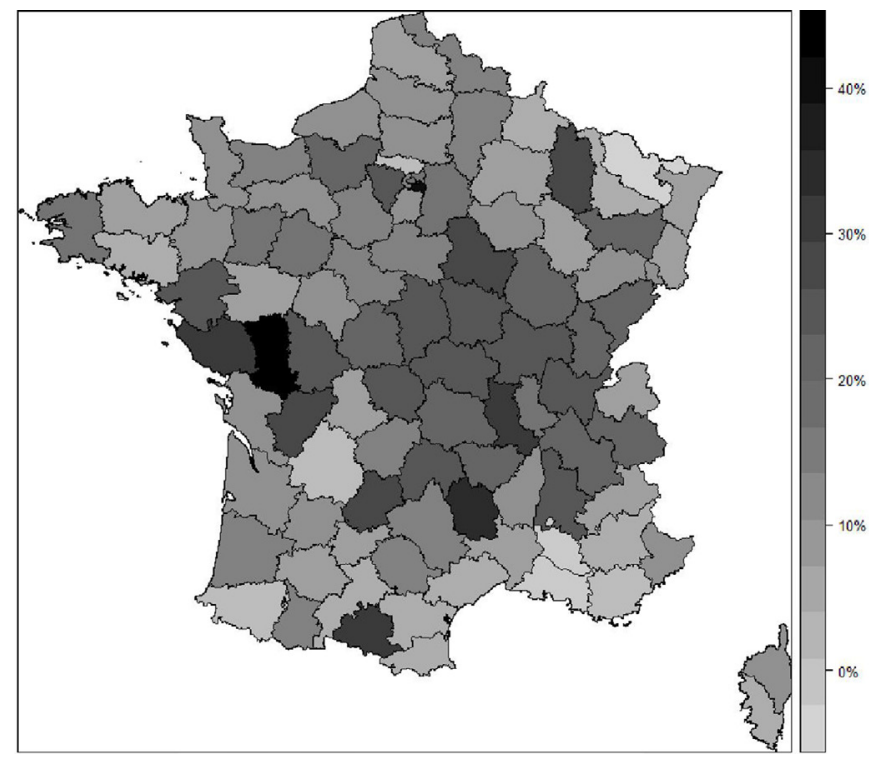

Figure 2 Response rate by French administrative geographical area. GPs, general practitioners. 


\begin{tabular}{|c|c|}
\hline Parameter & $\mathrm{n}=5425$ \\
\hline \multicolumn{2}{|l|}{ Gender } \\
\hline Female, n (\%) & $2914(53.7)$ \\
\hline Male, n (\%) & $2511(46.3)$ \\
\hline Age, mean age (SD) & $45.8(12.2)$ \\
\hline \multicolumn{2}{|l|}{ Type of practice } \\
\hline Alone, n (\%) & $1035(19.1)$ \\
\hline Mono-professional, n (\%) & $2226(41.0)$ \\
\hline Multi-professional, n (\%) & $2164(39.9)$ \\
\hline \multicolumn{2}{|c|}{ Type of multi-professional practice (among $n=2$ 164) } \\
\hline In multidisciplinary health house, n (\%) & $1411(65.2)$ \\
\hline In health centres, $\mathrm{n}(\%)$ & $269(12.4)$ \\
\hline Other, n (\%) & $484(22.4)$ \\
\hline Secretariat*, n (\%) & $4450(82.0)$ \\
\hline Physical, n & 3389 \\
\hline By phone, $n$ & 2017 \\
\hline Online, $\mathrm{n}$ & 1231 \\
\hline Unscheduled consultations, n (\%) & $1383(25.5)$ \\
\hline Receptionist, n (\%) & $1961(36.1)$ \\
\hline \multicolumn{2}{|l|}{ Region } \\
\hline Auvergne-Rhône-Alpes, n (\%) & $882(16.5)$ \\
\hline Bourgogne-Franche-Comté, n (\%) & $306(5.7)$ \\
\hline Bretagne, n (\%) & $274(5.1)$ \\
\hline Centre-Val de Loire, n (\%) & $183(3.4)$ \\
\hline Corse, n (\%) & $20(0.4)$ \\
\hline Grand Est, n (\%) & $344(6.4)$ \\
\hline Hauts-de-France, n (\%) & $467(8.7)$ \\
\hline Île-de-France, n (\%) & $892(16.6)$ \\
\hline Normandie, n (\%) & $259(4.8)$ \\
\hline Nouvelle-Aquitaine, n (\%) & $558(10.4)$ \\
\hline Occitanie, n (\%) & $432(8.1)$ \\
\hline Pays de la Loire, n (\%) & $394(7.3)$ \\
\hline Provence-Alpes-Côte d'Azur, n (\%) & $280(5.2)$ \\
\hline Regions of Outre-Mer, n (\%) & 70 (1.3) \\
\hline
\end{tabular}

*Secretariat means taking appointments and playing role of receptionist.

the main communication channels for information and guidelines.

GPs working in multi-professional group practices were more likely to have changed their activity since the beginning of the epidemic wave than GPs working in mono-professional group or single medical practices (aOR (adjusted OR): 1.32, 95\% CI 1.12 to $1.56, \mathrm{p}=0.001$ ). Women were more likely than men to have increased their ability to provide remote consultations, by phone, email or video (aOR: $1.13,95 \%$ CI 1.00 to $1.27, \mathrm{p}=0.04$ ). GPs working in mono-professional group practices (aOR:
$1.54,95 \%$ CI 1.30 to $1.84, \mathrm{p}<0.001)$ and GPs working in multi-professional group practices (aOR:2.84, 95\% CI 2.40 to $3.38, \mathrm{p}<0.001$ ) were more likely to have created specific pathways for COVID-19 suspected patients than GPs working in single medical practices. Age was not associated with organisational changes. The detailed data are summarised in table 4 and online supplemental table 6 .

\section{DISCUSSION}

\section{Statement of principal findings}

Our study showed that about three-quarters $(70.9 \%)$ of French GPs adapted their practices in the context of the COVID-19 epidemic. This adaptation occurred in a context of a lack of PPE. Working in a multi-professional group practice was strongly related to a higher level of adaptation. Development of remote consultations, mainly by developing phone consultations, concerned all GPs regardless of their type of practice.

\section{Strengths and limitations of this study}

Our survey is the first in France to present the adaptive strategies of GPs at a very early stage of the outbreak. Collection of data started 2 days before the publication of specific recommendations for primary care actors. Its publication during the survey period could have influenced our results.

Response rate to the survey was $11.8 \%$ of all the French active GPs. ${ }^{7}$ GPs belonged to all French counties: from $3.8 \%$ (Moselle) to $26.3 \%$ (Deux-Sèvres) with a median of $11.9 \%$. We were not able to distinguish between urban and rural practices.

This study, however, has some other limitations. First, knowing the responses were based on self-reports with a certain amount of socially desirable answers, we probably overestimated the adaptation. Second, the GPs who participated were younger than the average French GPs $(45.8$ vs 50.7$){ }^{7}$ The proportion of women was higher $(53.7 \%$ vs $44 \%)^{7}$ and they worked more frequently in multiprofessional settings $31 \%$ vs $15 \%{ }^{8}$ This over-representation of young GPs working in new models of practices may be explained by the recruitment through scientific societies, especially the National College of Academic GPs, which exists since 1983 and expanded with the creation of full academic positions for GPs in 2009 with the recruitment of active and young GPs. ${ }^{9}$ This selection bias could have resulted in an overestimation of the adaptation of practices in our sample. This may also underestimate the adaptive capacity of older GPs, who are also those less likely to be working in groups and multi-professional settings but may have other means of adaptation. Finally, due to the snowball strategy of recruitment we adopted for this survey, we decided not to use weighting measures.

Meaning of the study: possible explanations and implications for clinicians and policymakers

This study was launched 3 days before the quarantine strategy. However, in the context of the first epidemic 
Table 2 Personal protection equipment, organisational, hygiene and protective measures by type of practice

\begin{tabular}{|c|c|c|c|c|}
\hline $\mathbf{N}(\%)$ & $\begin{array}{c}\text { Alone } \\
n=1035\end{array}$ & $\begin{array}{l}\text { Mono-professional } \\
n=2226\end{array}$ & $\begin{array}{l}\text { Multi-professional } \\
\mathrm{n}=\mathbf{2 1 6 4}\end{array}$ & P value* \\
\hline \multicolumn{5}{|l|}{ Personal protection equipment } \\
\hline Protective masks ( $n=4699 / 5425)$ & $855(82.6)$ & $1933(86.8)$ & $1911(88.3)$ & $<0.001$ \\
\hline Protective glasses ( $n=1402 / 5425)$ & $312(30.1)$ & $514(23.1)$ & $576(26.6)$ & $<0.001$ \\
\hline Aprons ( $\mathrm{n}=1148 / 5425)$ & $193(18.6)$ & $415(18.6)$ & $540(25.0)$ & $<0.001$ \\
\hline Forehead thermometer $(n=4195 / 5425)$ & $774(74.8)$ & $1721(77.3)$ & $1700(78.6)$ & 0.058 \\
\hline \multicolumn{5}{|l|}{ Organisational changes } \\
\hline Secretariat $(n=4450 / 5425)$ & $597(57.7)$ & $1873(84.1)$ & $1980(91.5)$ & $<0.001$ \\
\hline Change on the secretariat $(n=2649 / 4450)$ & $333(55.8)$ & $1029(54.9)$ & $1287(65.0)$ & $<0.001$ \\
\hline Unscheduled consultations ( $n=1383 / 5425)$ & $361(34.9)$ & $489(22.0)$ & $533(24.6)$ & $<0.001$ \\
\hline Cancellation $(n=482 / 1383)$ & $125(34.6)$ & $171(35.0)$ & $186(34.9)$ & 0.994 \\
\hline Adaptation $(n=521 / 901)$ & $125(53.0)$ & $175(55.0)$ & $221(63.7)$ & 0.017 \\
\hline Change the activity $(n=3849 / 5425)$ & $706(68.2)$ & $1529(68.7)$ & $1614(74.6)$ & $<0.001$ \\
\hline $\begin{array}{l}\text { Creation of a dedicated area for suspected patients waiting } \\
(n=2315 / 5425)\end{array}$ & $299(28.9)$ & $752(33.8)$ & $1264(58.4)$ & $<0.001$ \\
\hline Increase remote consultation solutions ( $\mathrm{n}=3605 / 5425$ ) & $675(65.2)$ & $1436(64.5)$ & $1494(69.0)$ & 0.004 \\
\hline \multicolumn{5}{|l|}{ Hygiene and protective measures } \\
\hline Mask for the receptionist $(n=1418 / 1961)$ & $99(78.0)$ & $532(69.5)$ & $787(73.6)$ & 0.053 \\
\hline Hydroalcoholic solution for patients ( $n=2874 / 5425)$ & $424(41.0)$ & $1120(50.3)$ & $1330(61.5)$ & $<0.001$ \\
\hline $\begin{array}{l}\text { Communication supports (slideshows, posters and so on) } \\
\text { ( } n=4603 / 5425)\end{array}$ & $769(74.3)$ & $1910(85.8)$ & $1924(88.9)$ & $<0.001$ \\
\hline Disinfection of reception areas $(n=4308 / 5425)$ & $800(77.3)$ & $1725(77.5)$ & $1783(82.4)$ & $<0.001$ \\
\hline Mask all day $(n=2951 / 4699)$ & $488(57.1)$ & $1225(63.4)$ & $1238(64.8)$ & $<0.001$ \\
\hline Hands disinfection between each patient $(n=5322 / 5425)$ & $1007(97.3)$ & $2189(98.3)$ & $2126(98.2)$ & 0.104 \\
\hline
\end{tabular}

*Pearson's $\mathrm{X}^{2}$ test.

Table 3 (A) Increase of remote consultations and creation of a specific pathway by type of practice. (B) Communication channels for information and guidelines by type of practice

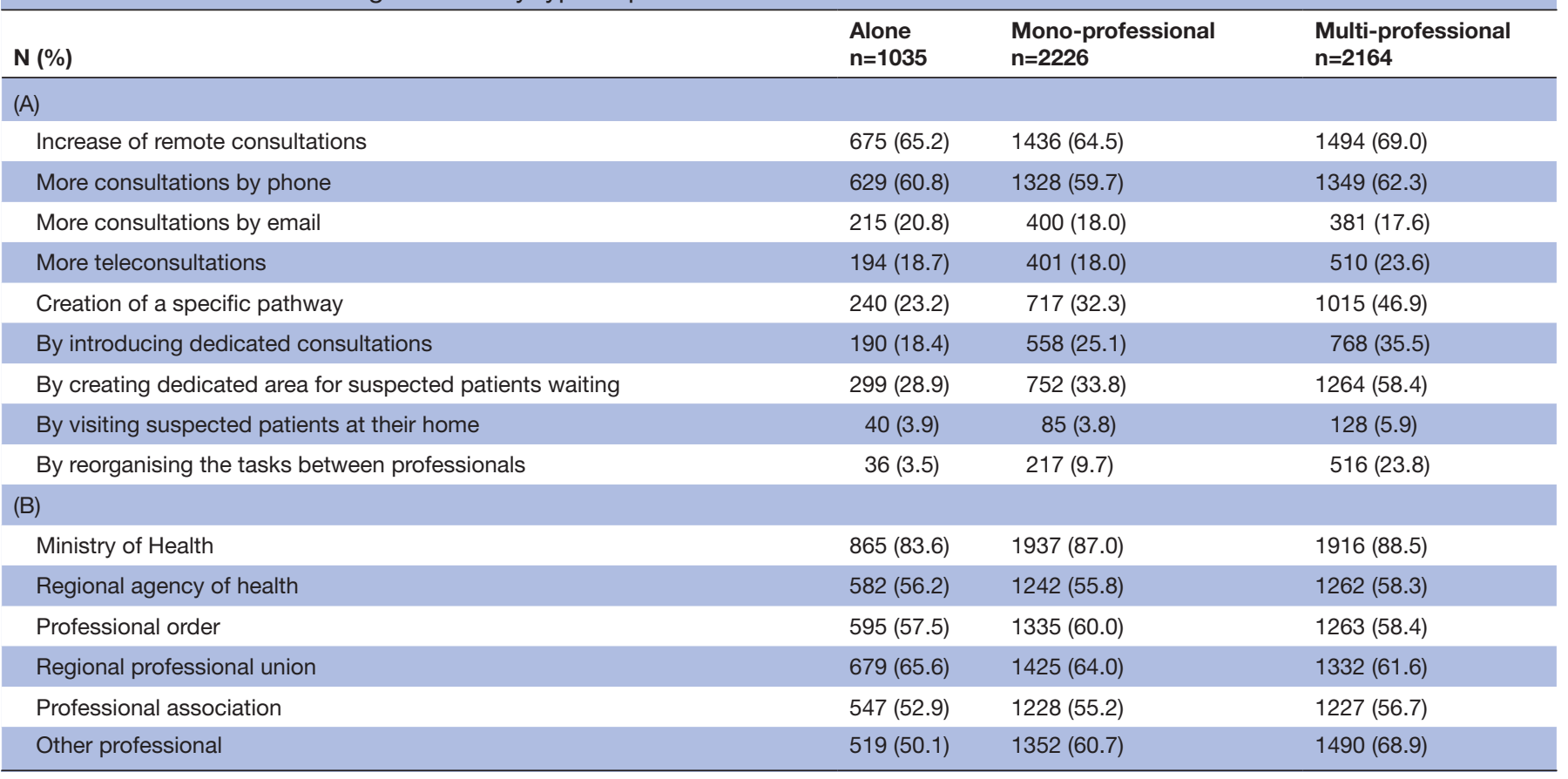


Table 4 Logistic regressions

«Did you change your activity since the outbreak? »

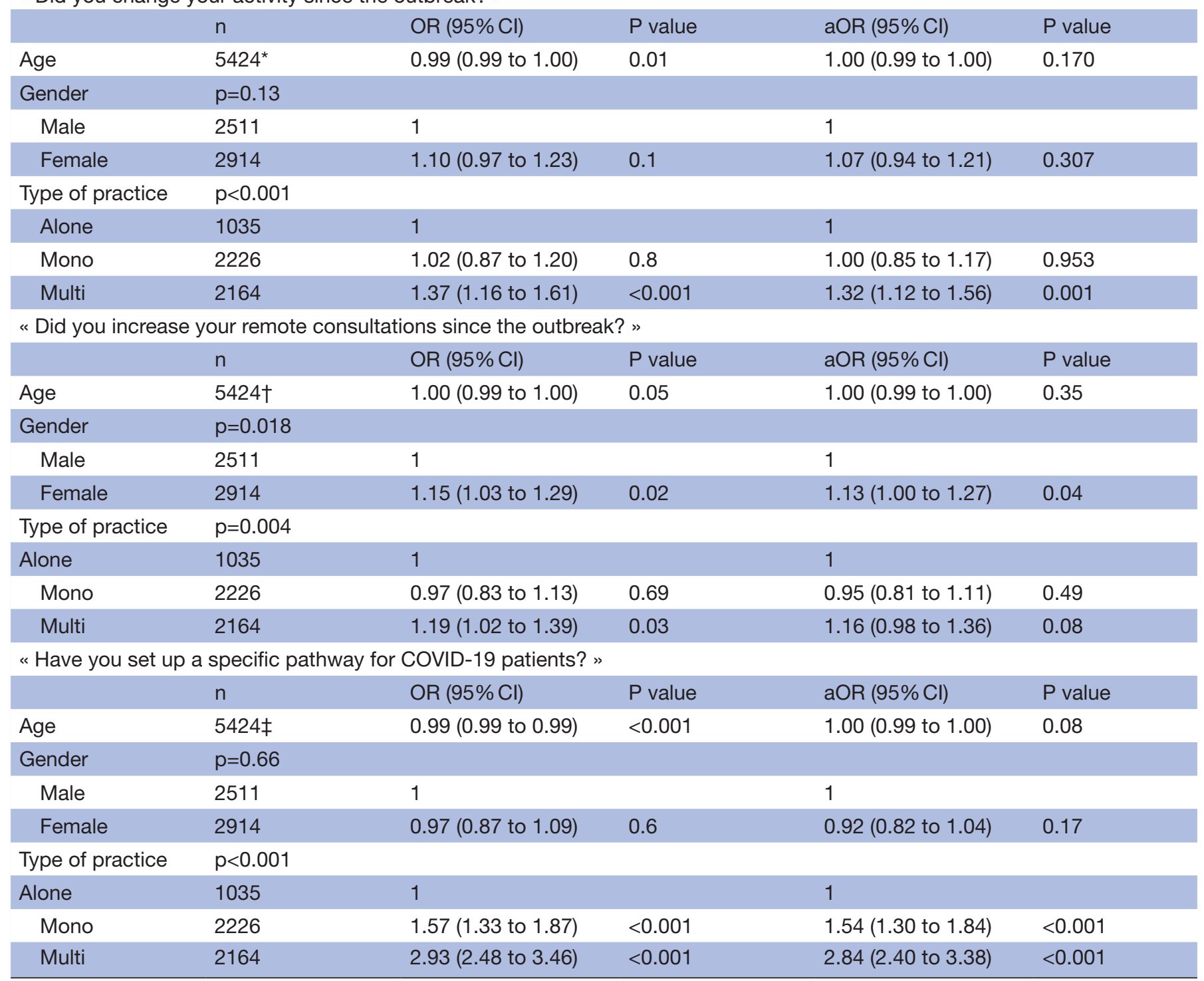

*T-test: $p=0.016$.

†T-test: $p=0.054$.

$\ddagger$ T-test: $p<0.001$.

aOR, adjusted OR.

wave, and despite the mobilisation and preparation of frontline actors such as GPs, the leadership of the health system has concentrated its efforts on lockdown and intensive care. According to some reports, many countries in western Europe have adopted a quite similar strategy. ${ }^{1011}$ The quarantine strategy induced a decrease of $40 \%$ in regular GP activities all over the country between 18 March and 31 March 2020. ${ }^{12}$ This decline was partly compensated by the increase in teleconsultations to represent a global decrease of 30\% of GPs' activities over the same period. This fast adaptation was supported by the valuation of teleconsultation for patients with COVID-19 symptoms being at the same price as a regular visit. Moreover, teleconsultations were not limited to any specific application. This increase in teleconsultations is probably due more to the increase in phone consultations than IT solutions. In addition, GPs who declared changing their activity in the survey declared increasing phone consultations $(91.7 \%)$ three times more often than those who declared increasing their video consultations $(30.7 \%)$. Nevertheless, the adoption of remote consultations did not compensate the lowered number of consultations and may increase unmet needs. This may in particular be due to the patients' behaviour since they were requested by health authorities, at the beginning of the quarantine, to stay at home and to call the emergency number or their regular GP only if they had severe COVID-19 symptoms. 
Most countries are now progressively ending the total lockdown strategy. GPs, as a part of the entire primary care sector were only lately involved in a national action plan to respond to the outbreak. They are now involved since the end of the quarantine strategy. ${ }^{13} 14$ PPE are now accessible, as well as RT-PCR (reverse transcription PCR) and serology tests. ${ }^{15}$ The issue for GPs and primary care sector is therefore to be involved in the management of the chronic phase outbreak and to simultaneously maintain accessibility and continuity of care for the whole population.

Our results tend to prove that team work and integrated form of practice in primary care reveal a promising model, not only to manage the demand of care induced by the epidemiological transition, ${ }^{16}$ but also during the infectious outbreak. As it exists a 'white plan' for hospitals in case of crisis, the primary care sector which has to play a key role needs a specific outbreak plan in the future.

Another study in the UK assessed the responsiveness and prioritisation of primary care consultation types for older adults during the COVID-19 pandemic. ${ }^{17}$ This database study showed an unprecedented reorganisation while retaining a focus on patients with increased complexity.

\section{Unanswered questions and future research}

The outbreak threat requires us to regularly adapt our practices and organisations, which requires a continuous assessment and research in the clinic, epidemiology and health services. Further surveys exploring territorial issues, such as coordination between primary care actors regarding continuity and accessibility of care, and the management of patients with COVID-19 and the population, are in progress.

\section{Author affiliations}

${ }^{1}$ Université Paris-Saclay, UVSQ, Univ. Paris-Sud, Inserm, Primary Care and Prevention, CESP, Villejuif, France

${ }^{2}$ Department of Family Medicine, UVSQ, Faculty of Health Sciences Simone Veil,

Montigny Le Bretonneux, France

${ }^{3}$ Conseil Scientifique du Collège National des Généralistes Enseignants (CNGE),

Paris, France

${ }^{4}$ Mission RESPIRE, EHESP-CNAMTS-IRDES - EA MOS 7348, 93210 la Plaine Saint

Denis, Saint-Denis, France

${ }^{5}$ Department of family medicine, UPEC, Faculty of Health, Créteil, France

${ }^{6}$ Société Française de Médecine Générale (SFMG), Issy-les-Moulineaux, France

${ }^{7}$ Inserm U955, Université Paris Est Créteil, Institut Mondor de Recherche

Biomédicale, équipe CEpiA (Clinical Epidemiology and Ageing), Créteil, France

${ }^{8}$ Institut Jean-François REY (IJFR), Paris, France

${ }^{9}$ Départment of family medicine, Université de Paris, Paris, France

${ }^{10}$ Départment of family medicine, Université de Saint Etienne, Saint-Étienne, France

${ }^{11}$ Départment of family medicine, Université de Rouen, Rouen, France

\section{Twitter Olivier Saint-Lary @PIFOP}

Acknowledgements The authors are indebted to Véronique Orcel for her helpful review of the manuscript and to Accord network (Assembler, Coordonner, Comprendre, Rechercher, Débattre en soins primaires) for their reflection and help in the construction of the questionnaire. ACCORD is composed of the National College of GP Instructors (CNGE), French Society of General Practice (SFMG), National Federation of Multiprofessional Health Houses (AVECSanté), Research Institute of Health Care Centres (IJFR), URE RETINES (Risque, Epidémiologie, Territoire, INformations, Education en santé) Université de Nice, National Association of Health Teams in Primary Care (ASALEE), Mission RESPIRE (EHESP) and the Midwifery Department, EA 7285, Versailles Saint Quentin University group.

Contributors OS-L, SG, YB and VR designed the study. SG, SGa, JLB, and MS contributed to the database preparation. SGa, JLB and YB analysed data. OS-L, SG and $Y B$ drafted the manuscript. VR, MS, PF and SG critically revised the manuscript. All authors commented on and approved the draft and final manuscripts. All authors agree to be accountable for all aspects of the work in ensuring that questions related to the accuracy or integrity of any part of the work are appropriately investigated and resolved.

Funding The authors have not declared a specific grant for this research from any funding agency in the public, commercial or not-for-profit sectors.

Disclaimer Olivier Saint-Lary (the manuscripts' guarantor) affirms that the manuscript is an honest, accurate and transparent account of the study being reported; that no important aspects of the study have been omitted; and that any discrepancies from the study as planned have been explained.

Map disclaimer The depiction of boundaries on this map does not imply the expression of any opinion whatsoever on the part of BMJ (or any member of its group) concerning the legal status of any country, territory, jurisdiction or area or of its authorities. This map is provided without any warranty of any kind, either express or implied.

Competing interests All authors have completed the Unified Competing Interest form (available on request from the corresponding author) and declare: no support from any organisation for the submitted work; no financial relationships with any organisations that might have an interest in the submitted work in the previous three years, no other relationships or activities that could appear to have influenced the submitted work.

Patient consent for publication Not required.

Ethics approval The study protocol was approved by the ethics committee of the National College of Academic GPs (CNGE, IRB number 00010804).

Provenance and peer review Not commissioned; externally peer reviewed.

Data availability statement Data are available upon reasonable request.

Supplemental material This content has been supplied by the author(s). It has not been vetted by BMJ Publishing Group Limited (BMJ) and may not have been peer-reviewed. Any opinions or recommendations discussed are solely those of the author(s) and are not endorsed by BMJ. BMJ disclaims all liability and responsibility arising from any reliance placed on the content. Where the content includes any translated material, BMJ does not warrant the accuracy and reliability of the translations (including but not limited to local regulations, clinical guidelines, terminology, drug names and drug dosages), and is not responsible for any error and/or omissions arising from translation and adaptation or otherwise.

Open access This is an open access article distributed in accordance with the Creative Commons Attribution Non Commercial (CC BY-NC 4.0) license, which permits others to distribute, remix, adapt, build upon this work non-commercially, and license their derivative works on different terms, provided the original work is properly cited, appropriate credit is given, any changes made indicated, and the use is non-commercial. See: http://creativecommons.org/licenses/by-nc/4.0/.

ORCID iD

Olivier Saint-Lary http://orcid.org/0000-0003-3731-3476

\section{REFERENCES}

1 Sarti TD, Lazarini WS, Fontenelle LF, et al. What is the role of primary health care in the COVID-19 pandemic? Epidemiol Serv Saude 2020;29:e2020166.

2 Greenhalgh T, Koh GCH, Car J. Covid-19: a remote assessment in primary care. BMJ 2020;368:m1182.

3 Ministry of Health. Guidelines for the city management of symptomatic patients in the epidemic phase of covid-19, 2020 Available: https://solidarites-sante.gouv.fr/IMG/pdf/covid-19_ doctrine_ville_v16032020finalise.pdf

4 Kringos DS, Boerma WGW, Hutchinson A, et al. Building primary care in a changing Europe, 2015. Available: http://www.euro.who. int/en/about-us/partners/observatory/publications/studies/buildingprimary-care-in-a-changing-europe

5 Chaput $\mathrm{H}$. More than $80 \%$ of general practitioners under 50 practice in a group. DRESS, 2019. Available: http://www.epsilon.insee.fr/jspui/ bitstream/1/95815/1/er1114.pdf 
6 Alrabie N. Integrating professionals in French multi-professional health homes: fostering collaboration beyond the walls. Health Serv Manage Res 2020;33:86-95.

7 French National Health Insurrance. Statistical data on the demographics of French health professionals. Ameli.fr, 2020. Available: https://www.ameli.fr/l-assurance-maladie/statistiques-etpublications/donnees-statistiques/professionnels-de-sante-liberaux/ demographie/effectifs-et-densite.php

8 Marbot C, French Ministry of Health. Portrait des professionnels de santé - édition 2016. Paris: DREES, 2016. https://drees.solidaritessante.gouv.fr/IMG/pdf/gfs-2016_mel_301117.pdf

9 Barais M, Laporte C, Schuers M, et al. Cross-Sectional multicentre study on the cohort of all the French junior lecturers in general practice. Eur J Gen Pract 2018;24:99-105.

10 Thornton J. Covid-19: how coronavirus will change the face of general practice forever. BMJ 2020;368:m1279.

11 Spina S, Marrazzo F, Migliari M, et al. The response of Milan's emergency medical system to the COVID-19 outbreak in Italy. Lancet 2020;395:e49-50.
12 ameli.fr. Communique_des_depenses_Fin_mars_2020_03.pdf, 2020. Available: https://www.ameli.fr/fileadmin/user_upload/documents/ Communique_des_depenses_Fin_mars_2020_03.pdf

13 Lim WH, Wong WM. COVID-19: notes from the front line, Singapore's primary health care perspective. Ann Fam Med 2020;18:259-61.

14 French Ministry of Health. Ambulatory care: recommendations Covid-19 and support. Ministère des Solidarités et de la Santé, 2020. Available: http://solidarites-sante.gouv.fr/soins-et-maladies/maladies/ maladies-infectieuses/coronavirus/professionnels-de-sante/article/ en-ambulatoire-recommandations-covid-19-et-prise-en-charge

15 French High Authority for Health. Place des tests sérologiques dans La stratégie de prise en charge de la Maladie COVID-19. Haute Autorité de Santé, 2020. Available: https://www.has-sante.fr/jcms/p_ 3179992/fr/place-des-tests-serologiques-dans-la-strategie-de-priseen-charge-de-la-maladie-covid-19

16 Wynn A, Moore KM. Integration of primary health care and public health during a public health emergency. Am J Public Health 2012;102:e9-12.

17 Joy M, McGagh D, Jones N, et al. Reorganisation of primary care for older adults during COVID-19: a cross-sectional database study in the UK. Br J Gen Pract 2020;70:e540-7. 